S. UMEZU, G. DOS PASSOS GOMES, T. YOSHINAGA, M. SAKAE, K. MATSUMOTO, T. IWATA, I. ALABUGIN, M. SHINDO* (FLORIDA STATE UNIVERSITY, USA AND KYUSHU UNIVERSITY, KASUGA, JAPAN)

Regioselective One-Pot Synthesis of Triptycenes via Triple-Cycloadditions of Arynes to Ynolates

Angew. Chem. Int. Ed. 2017, 56, 1298-1302.

\title{
Three Benzynes and the Ynolate
}<smiles>[B]C([B])([B])C(=O)OCC</smiles>

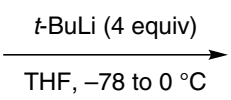<smiles>[R]C#CO</smiles>

Substrate scope:

\begin{tabular}{lllll}
\hline Entry & $\mathrm{R}$ & $\mathrm{X}$ & Conditions & Yield (\%) \\
\hline 1 & $\mathrm{Me}$ & $\mathrm{H}$ & $\mathrm{A}$ & 42 \\
2 & $i-\mathrm{Pr}$ & $\mathrm{H}$ & $\mathrm{A}$ & 35 \\
3 & $n-\mathrm{Bu}$ & $\mathrm{H}$ & $\mathrm{A}$ & 52 \\
4 & $t-\mathrm{Bu}$ & $\mathrm{H}$ & $\mathrm{A}$ & 39 \\
5 & $\mathrm{Ph}$ & $\mathrm{H}$ & $\mathrm{A}$ & 27 \\
6 & $\mathrm{Me}$ & $\mathrm{OMe}$ & $\mathrm{B}$ & 69 \\
7 & $i-\mathrm{Pr}$ & $\mathrm{H}$ & $\mathrm{A}$ & 39 \\
8 & $n-\mathrm{Bu}$ & $\mathrm{OMe}$ & $\mathrm{B}$ & 48 \\
9 & $\mathrm{Hex}$ & $\mathrm{OMe}$ & $\mathrm{B}$ & 37 \\
10 & $\mathrm{Ph}$ & $\mathrm{H}$ & $\mathrm{A}$ & 37 \\
\hline
\end{tabular}

\section{Examples of disubstituted benzynes:}

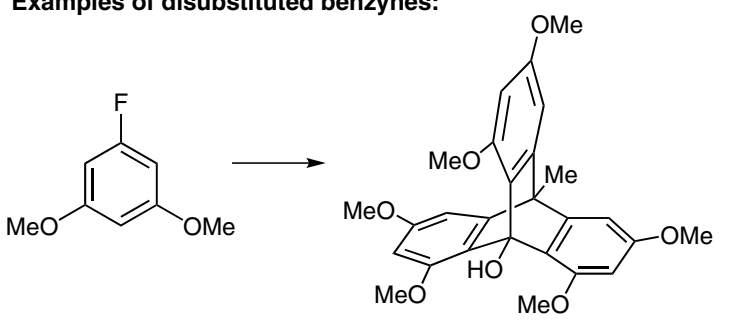

$39 \%$ yield
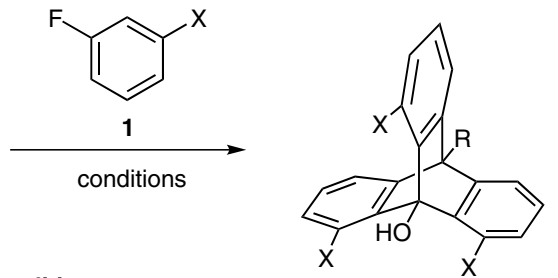

Conditions

A: 1 ( 6 equiv), then $n$-BuLi (4 equiv) addition over $1 \mathrm{~h}$

B: 1 (4 equiv), then $n$-BuLi (4 equiv) addition over 5 min $-20^{\circ} \mathrm{C}$
Gategory

Synthesis of

Materials and

Unnatural Products

\section{Key words}

triptycenes

arynes

ynolates
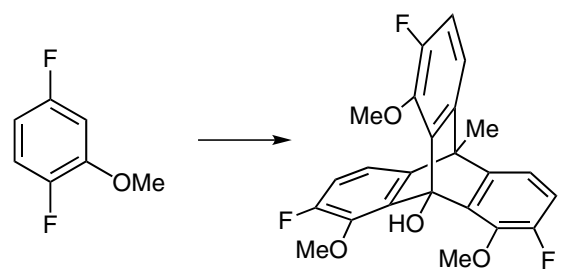

$30 \%$ yield
Significance: The triptycene structure is a remarkable scaffold that is frequently employed in functional materials as a result of its three dimensional, noncompliant structures and the interstitial space around the molecule. Most syntheses are based on a Diels-Alder cycloaddition between anthracene and an aryne. The authors describe a one-pot synthesis of triptycenes that proceeds through three cycloadditions of arynes to ynolates.
Comment: The approach of formally inserting three arynes into an alkyne is a new and powerful way to obtain both simple and substituted triptycenes. Calculations provide an insight into the mechanism and explain the high regioselectivity (head-to-head-to-head). 